\title{
Experimental study on mechanical and acid-alkali properties of reactive magnesia carbonated-stabilized soil
}

\author{
Cai Guanghua ${ }^{\text {i) }}$, Liu Songyu ${ }^{\text {ii)}}$, Cao Jingjing ${ }^{\text {iii) }}$ and Zheng $\mathrm{Xu}^{\text {iv) }}$

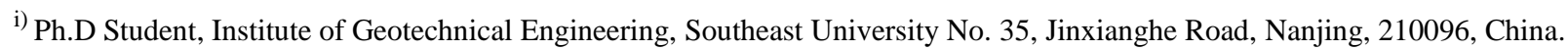 \\ ii) Professor, Institute of Geotechnical Engineering, Southeast University No. 35, Jinxianghe Road, Nanjing, 210096, China. \\ iii) Graduate Student, Institute of Geotechnical Engineering, Southeast University No. 35, Jinxianghe Road, Nanjing, 210096, China.

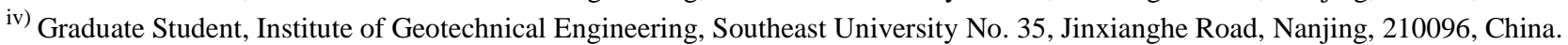

\begin{abstract}
This paper aims at investigating a rapid and environmentally friendly soil stabilization method to significantly increase the strength of carbonated reactive magnesia $(\mathrm{MgO})$-treated soil by exposing it to substantial quantities of $\mathrm{CO}_{2}$. Soil specimens treated with 10,15 and $20 \%$ reactive $\mathrm{MgO}$ were subjected to accelerated carbonation for $1.5,3$, 4.5, 6, and 12 hour. Later, specimens' weight, permeability, unconfined compressive strength and $\mathrm{pH}$ were measured after carbonation. The results can be summarized as follows: the weight of carbonated soils increases with dosage and carbonation time; the permeability coefficient increases with the increase of porosity and the decrease of dosage of reactive $\mathrm{MgO}$, and it decreases first and then increases with the carbonation time; the strength of carbonated specimens increases with the increase of the dosage, and it increases quickly with increasing carbonation time in first 3 hours and then keeps stable. The strength reaches or exceeds the strength of cement-stabilized soils for 28 days with the same dosage; the $\mathrm{pH}$ value first increases and then decreases generally with reactive $\mathrm{MgO}$ content increasing, and a critical carbonation time (about 3 hour) exists in terms of the varying trend.
\end{abstract}

Keywords: reactive magnesia, carbonation, permeability, strength, $\mathrm{pH}$

\section{INTRODUCTION}

In recent years, with the rapid development of urbanization and industrialization, the urban infrastructures and transportations have experienced a rapid development, and a great number of engineering constructions demand high-quality foundation reinforcement and curing materials. The Deep Soil Mixing can help to achieve significant improvement of mechanical and physical properties for the existing soil by mixing it with Portland cement (PC) or other curing agents, and has a worldwide use in strengthening soft ground. The cement-stabilized soil, generally produced in the formation of powder or slurry, has higher strength and compressibility than the native soil, and can effectively reduce the settlement and increase the stability of soft ground (Liu et al., 2006). The strength development of cement stabilized soil is mainly through hydration (Yi et al., 2013). However, the formation of hydration products and the strength growth are relatively slow; the PC industry needs high calcination temperature $\left(>1450^{\circ} \mathrm{C}\right)$ and energy consumption $(5000$ $\mathrm{MJ} / \mathrm{t} \mathrm{PC}$ ), and has been considered as one of the major causes of the increase in the atmospheric concentration of $\mathrm{CO}_{2}\left(\sim 0.95 \mathrm{t} \mathrm{CO}_{2} / \mathrm{t} \mathrm{PC}\right)$, which may cause species extinction and the rise of the global temperature, as reported in previous studies (Liska and Al-Tabbaa, 2009; Vandeperre et al. 2008).

Therefore, great efforts have been done to seek alternatives of PC in order to reduce $\mathrm{CO}_{2}$ emissions or to develop innovative technologies to deal with $\mathrm{CO}_{2}$. Previous technologies included physical, chemical and biological methods. Meanwhile, many researchers have started to study the industrial by-products or industrial waste to replace traditional curing agents in recent years (Liska et al. 2008). Harrison (2001) invented $\mathrm{MgO}$ cement and showed its superiority in engineering properties and environment. The performances are: reactive $\mathrm{MgO}$ is calcinated from magnesite at a low kiln temperature $\left(<750^{\circ} \mathrm{C}\right)$ and lower energy consumption $(1480 \mathrm{MJ} / \mathrm{t} \mathrm{MgO})$ with regard to production compared with $\mathrm{PC}$ production $\left(>1450^{\circ} \mathrm{C}\right)$, significantly reducing the fuel consumption. Furthermore, reactive $\mathrm{MgO}$ can absorb the $\mathrm{CO}_{2}$ emitted from the industrial practices during carbonation process, and possess the potential advantages of a low-carbon in environmental protection and high efficient in the constructions. Quantities of investigations on the $\mathrm{MgO}$ cement were performed by 
University of Cambridge (Vandeperre and Al-Tabbaa, 2007; Vandeperre et al. 2008; Yi et al., 2013).

Subsequently, another innovative method was proposed that reactive $\mathrm{MgO}$ was employed as a binder for stabilizing soft soils when subjected to carbonation. Yi et al. (2013) performed the preliminary experiments of sandy soil by the tri-axial carbonation apparatus and the carbonated mixing-pile technology, and proved that the carbonation method is feasible; Liu and $\mathrm{Li}$ (2015) studied the effects of $\mathrm{MgO}$ activity on the silty clay carbonation. The results showed that their carbonation can almost complete within 3 to 6 hour and 24 hour for sandy soils and clay soils, respectively; and the higher $\mathrm{MgO}$ activity is, the higher the strength is. What's more, magnesium compounds, which had great contribution to strength improvement, were found such as nesquehonite, hydromagnesite and dypingite. Cai et al. $(2015 a, b)$ studied the strength and deformation characteristics of carbonated reactive $\mathrm{MgO}$-treated silt and built the prediction model of strength.

Nevertheless, the physical, mechanical, hydraulic conductivity and soil $\mathrm{pH}$ of carbonated silt have not been investigated. In this paper, the carbonation experiments of reactive $\mathrm{MgO}$-treated silt with 3 different $\mathrm{MgO}$ contents (10, 15 and 20\%) were performed for 5 different carbonation times $(1.5,3,4.5$, 6 and 12 hour). Then, the effects of reactive $\mathrm{MgO}$ contents and carbonation times on the weight growth, macro porosity, permeability, strength and $\mathrm{pH}$ of carbonated reactive $\mathrm{MgO}$-treated silt are studied. Finally, the relationship between the hydraulic conductivity and macro porosity is discussed.

\section{Experimental program}

\subsection{Materials}

In this study, the silt and reactive $\mathrm{MgO}$ was obtained from Yancheng, Liaoning, China. The natural water content of soil is about $26.1 \%$ and its basic physico-chemical properties are summarized in Table 1. Compaction characteristics curve of the tested soil is shown in Fig. 1. Fig. 2 shows the grain size distributions of silt and reactive $\mathrm{MgO}$; Table 2 presents the chemical compositions of materials.

Table 1. Physico-chemical properties of materials.

\begin{tabular}{lll}
\hline Index & Soil & Reactive $\mathrm{MgO}$ \\
\hline Liquid limit, $w_{\mathrm{L}}(\%)$ & 33.8 & $\mathrm{ND}$ \\
Plastic limit, $w_{\mathrm{P}}(\%)$ & 23.9 & $\mathrm{ND}$ \\
Plasticity index & 9.9 & $\mathrm{ND}$ \\
Specific gravity, $G_{\mathrm{s}}$ & 2.71 & 2.25 \\
Soil classification & $\mathrm{ML}$ & $\mathrm{ND}$ \\
$\mathrm{pH} \quad$ (water/soil=1:1) & 8.78 & $\mathrm{ND}$ \\
\hline
\end{tabular}

Table 2. Mineralogical compositions of materials.

\begin{tabular}{cccccccc}
\hline Composition & $\mathrm{MgO}$ & $\mathrm{Al}_{2} \mathrm{O}_{3}$ & $\mathrm{CaO}$ & $\mathrm{SiO}_{2}$ & $\mathrm{Fe}_{2} \mathrm{O}_{3}$ & $\mathrm{MnO}$ & $\mathrm{LOI}$ \\
\hline silt & 2.18 & 11.9 & 5.57 & 62.5 & 3.3 & 0.057 & 10 \\
Magnesia & 85.3 & 0.24 & 2.46 & 5.58 & 0.22 & 0.01 & 5.87 \\
\hline
\end{tabular}
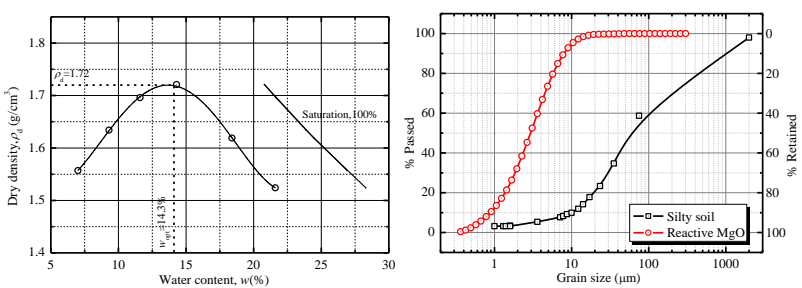

Fig. 1. Soil compaction curve. Fig. 2. Grain size distributions.

\subsection{Specimen preparation}

Preparation and carbonation of specimens were the same as those used by Cai et al. $(2015 a, b)$. In this study, reactive $\mathrm{MgO}$ contents were 10,15 and $20 \%$, and the gravimetric water content was approximately $25 \%$, near the natural water content. The cylindrical specimens $(\Phi 50 \times H 100 \mathrm{~mm})$ were made by using the hydraulic jack when the mixtures were homogenous, Next, specimens, after whose sizes and weight were measured, were put into the sealed setup contained $99.9 \% \mathrm{CO}_{2}$ gas, and then subjected to the forced carbonation under 200 $\mathrm{kPa}$ for $1.5,3,4.5,6$ and 12 hour. There were four parallel samples in each group, two of which were used for macro porosity and permeability tests, the other two of which were used for unconfined compression and chemical tests. Figure 3 shows the picture of the carbonation apparatus.

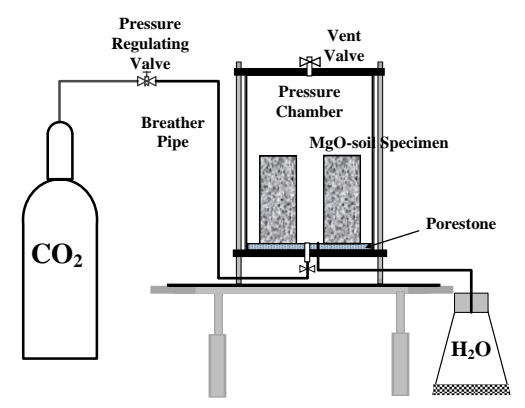

Fig. 3. The carbonation apparatus.

\subsection{Testing method}

After carbonation, the specimens were taken out and exposed to an atmospheric environment for about 30 minutes' air-drying in order to wipe off the apparent moisture. The specimens were weighed and the unconfined compressive tests were conducted as per ASTM D5102-09 and the averages of two compressive strength values $\left(q_{u}\right)$ were determined. Next, the broken specimen was crushed and dried in an oven under the temperature of $50{ }^{\circ} \mathrm{C}$ to a constant mass because nesquehonite $\left(\mathrm{MgCO}_{3} \cdot 3 \mathrm{H}_{2} \mathrm{O}\right)$ of crystalline compounds was unstable at temperatures up to $50^{\circ} \mathrm{C}$ (Unluer, et al. 2011). Furthermore, Gerven et al. (Van Gerven et al., 2004) proposed the macro-porosity testing method of samples, and the calculation formula was as Eq. (1):

$$
n(\%)=\left(m_{w}-m_{d}\right) / V
$$


where $n$ is porosity; $m_{w}$ is wet weight after saturation $(\mathrm{g}) ; m_{d}$ is dry weight $(\mathrm{g}) ; V$ is the volume $\left(\mathrm{cm}^{3}\right)$. In order to measure the porosity, the specimens are dried to measure the dry weight $\left(m_{d}\right)$, and then saturated for 48 hour to measure the wet weight $\left(m_{w}\right)$; finally, the penetration test is applied for the saturated specimens by three axis flexible permeameter, with confined pressure of $200 \mathrm{kPa}$ and osmotic pressure of $150 \mathrm{kPa}$. The measurement of permeability starts when the hydraulic discharge per unit time basically stable.

Next, oven-dried carbonated soil was sieved $(<2$ $\mathrm{mm}$ ), weighed out approximately $10 \mathrm{~g}$, placed into plastic bottles and added approximately $10 \mathrm{~mL}$ of distilled water. And then the bottles with mixtures should be capped in case of absorbing $\mathrm{CO}_{2}$ in air. Three identical samples were prepared for the measurement of $\mathrm{pH}$ value in the laboratory $\left(20 \pm 2^{\circ} \mathrm{C}\right)$. The triplicate tested results were limited in a relative small deviation and the average value was considered as the $\mathrm{pH}$ value.

\section{Results and discussion}

\subsection{Physical properties}

Existing studies show that the weight of reactive $\mathrm{MgO}$-treated specimens can increase to different extent after carbonation (Yi, et al., 2013; Liu and Li, 2014; Cai, et al. 2015a,b). Figure 4 shows the changes of weight growth with carbonation time. The weight of specimens increases with carbonation time, especially in the first 3 hour, the weight growth is the largest. With carbonation time continuing, the weight growth experiences from gradual to stable. It can also be seen from Fig. 4 that the weight growth increases with the increase of reactive $\mathrm{MgO}$ content. This can be attributed to the hydration of reactive $\mathrm{MgO}$ and carbonation of brucite by absorbing $\mathrm{CO}_{2}$, which result in the obvious weight growth. Accordingly, the higher dosage of reactive $\mathrm{MgO}$ is, the more $\mathrm{CO}_{2}$ absorbed is, leading to the higher weight growth of specimens. Figure 5 describes that the macro porosity changes with carbonation time. It can be seen from Fig. 5 that the macro porosity increases with the reactive $\mathrm{MgO}$ content decreasing, and macro porosity has a slight change with carbonation time. Because carbonation causes some expansion of specimens and the carbonation products can fill the pores of specimens.

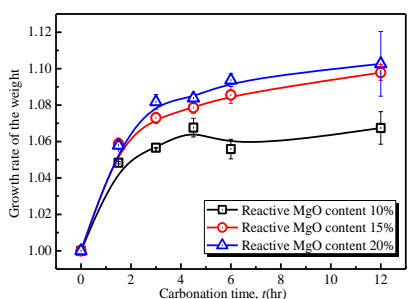

Fig. 4. Variations in weight with carbonation time.

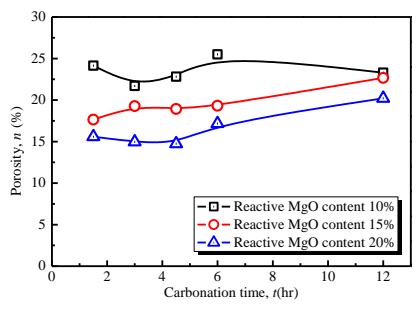

Fig. 5. Variations in porosity with carbonation time.

\subsection{Permeability properties}

Figure 6 depicts that the hydraulic conductivity of carbonated specimens changes with duration time. The permeability coefficients of specimens can achieve stability quickly, presenting the reducing permeability coefficient with increasing dosage. Comparative analysis between eventual permeability coefficient and carbonation time is shown in Fig. 7.
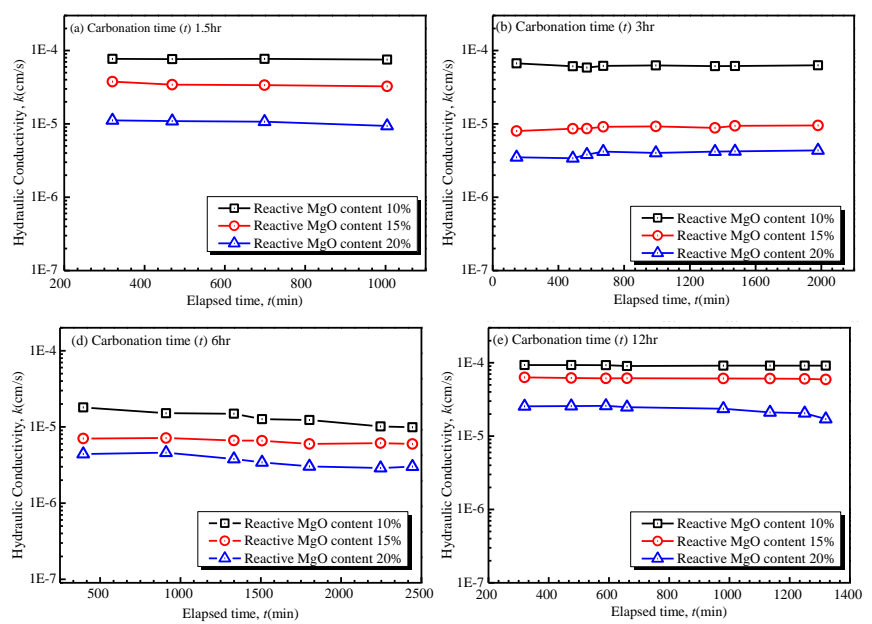

Fig. 6. Permeability changes with elapsed time.

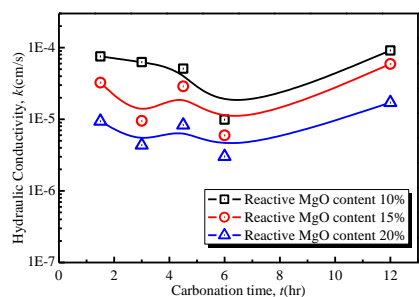

Fig. 7. Permeability changes with carbonation time.

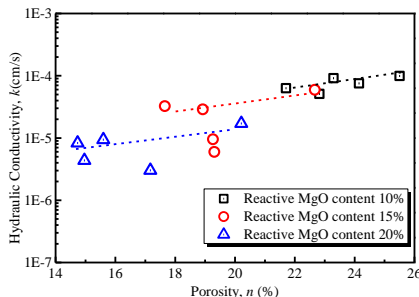

Fig. 8. Relationship between permeability and porosity.
The change of permeability coefficient with carbonation time presents the trend of decreasing at first and increasing after 6 hour. The porosity and permeability are the minimum after the carbonation for 6 hour, and the permeability coefficients of specimens increase when the carbonation time over 6 hour. The reasons are that: (1) with the increase of carbonation time, the number of the cementing products generated increase, and the filling effect is enhanced, which makes the porosity change obviously; (2) for low dosage specimens, cementing effect from carbonation is weak, and the pressure of long time promotes the moisture-air exchange of specimens without confining pressure; (3) the impurity restrains the carbonation, both of them promote the micro-cracks in specimens, resulting the porosity and permeability increase under long time carbonation (Cai, et al. 2015a,b). Figure 8 presents the relationship between permeability coefficient and porosity. It shows that permeability coefficient increases with the porosity. 


\subsection{Mechanical properties}

Figure 9 shows variations in unconfined compressive strength with carbonation time. It can be seen from Fig. 9 that the strength of carbonated soils increases until 3 hour's carbonation and then becomes stable with the carbonation time continuing, with the strength at stability lower than the maximum. The strength of carbonated reactive $\mathrm{MgO}$ soils can reach or exceed the strength of PC stabilized soils for 28 days in a few hours under the same dosage. It can be found that the strength increases with the dosage of reactive $\mathrm{MgO}$. The main reason is that carbonation form different magnesium carbonates, which include nesquehonite $\left(\mathrm{MgCO}_{3} \cdot 3 \mathrm{H}_{2} \mathrm{O}\right)$, dypingite $\left(\mathrm{Mg}_{5}\left(\mathrm{CO}_{3}\right)_{4}(\mathrm{OH})_{2} \cdot 5 \mathrm{H}_{2} \mathrm{O}\right)$ hydromagnesite $\left(\mathrm{Mg}_{5}\left(\mathrm{CO}_{3}\right)_{4}(\mathrm{OH})_{2} \cdot 4 \mathrm{H}_{2} \mathrm{O}\right)$ and so on, among them the growth of fibrous and acicular crystals of $\mathrm{MgCO}_{3} \cdot 3 \mathrm{H}_{2} \mathrm{O}$ is the main contributor to the strength growth; Besides, hydromagnesite and dypingite have obvious filling effects on pores (Yi, et al. 2013).

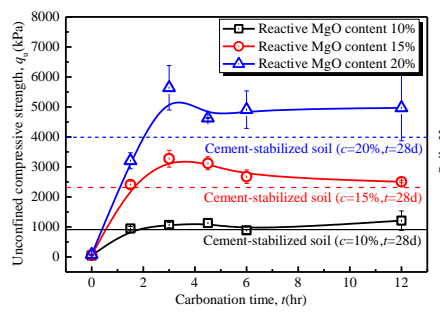

Fig. 9. Variations in strength with carbonation time.

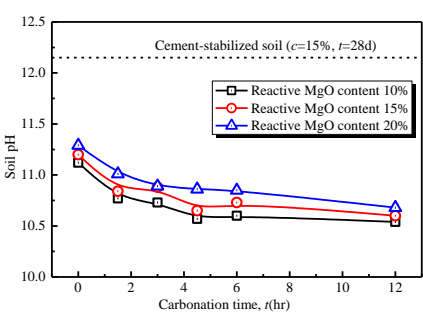

Fig. 10. Variations in soil $\mathrm{pH}$ with carbonation time.

\subsection{Chemical properties}

Figure 10 depicts the change in $\mathrm{pH}$ of carbonated soils with carbonation time. It can be seen that $\mathrm{pH}$ of soils increases with the increasing dosage; $\mathrm{PH}$ decreases slowly and finally becomes stable with the continuing carbonation time, and $\mathrm{pH}$ decreases obviously at first few hours. The reasons of the above results were that there were different amounts of $\mathrm{MgO}$ and $\mathrm{Mg}(\mathrm{OH})_{2}$ ingredients in the reactive $\mathrm{MgO}$ carbonated stabilized soil while pore fluid contained mainly varieties of ions such as magnesium $\left(\mathrm{Mg}^{2+}\right)$, hydroxide $\left(\mathrm{OH}^{-}\right)$, which played a positive role in promoting the increase of $\mathrm{pH}$ value (see Eq. (2)). However, with carbonation time continuing, $\mathrm{MgO}$ and $\mathrm{Mg}(\mathrm{OH})_{2}$ in admixtures were gradually consumed for the formation of insoluble compounds, which made the concentration of $\mathrm{OH}^{-}$in the pore solution reduce, resulting in correspondingly reducing the $\mathrm{pH}$ value.

$$
\mathrm{MgO}+\mathrm{H}_{2} \mathrm{O} \rightarrow \mathrm{Mg}(\mathrm{OH})_{2} \rightarrow \mathrm{Mg}^{2+}+2 \mathrm{OH}^{-}
$$

\section{Conclusions}

Based on results, conclusions can be drawn:

1) The weight of carbonated soils increases with dosage and carbonation time, and the weight growth is the maximum in first 3 hour.
2) The permeability coefficient increases with the increase of porosity and decreases with the increase of dosage of reactive $\mathrm{MgO}$. It decreases first and then increases with the carbonation time.

3) The strength increases with dosage, and increases quickly with carbonation time during first 3 hours, then keeps stable, and it reaches or exceeds the strength of cement-stabilized soils for 28 days at the same dosage.

4) The $\mathrm{pH}$ first increases and then decreases with reactive $\mathrm{MgO}$ content increasing.

\section{ACKNOWLEDGEMENTS}

This research is financially supported by the NSFC (No. 51279032), "12th 5-yr" National Technology Support Program of China (No. 2012BAJ01B02-01), and "the Fundamental Research Funds for the Central Universities" and Graduate Student Scientific Research Innovation Projects of Jiangsu Province (KYLX_0147).

\section{REFERENCES}

1) Cai, G.H., Liu, S.Y., Du, Y.J., Zhang, D.W., Zheng, X. (2015a). Strength and deformation characteristics of carbonated reactive magnesia treated silt soil. Journal of Central South University. 22(5):1859-1868.

2) Cai, G.H., Du, Y.J., Liu, S.Y., D. N. Singh (2015b). Physical properties, electrical resistivity and strength characteristics of carbonated silty soil admixed with reactive magnesia [J]. Canadian Geotechnical Journal. doi:10.1139/cgj-2015-0053.

3) Harrison AJW. Reactive Magnesium Oxide Cements. Australian Patent. 2001; 01/55049A1.

4) Liska M, Al-Tabbaa A. (2009). Ultra-green construction: reactive magnesia masonry products $[\mathrm{J}]$. Waste and Resource Management, 162(4): 185-196.

5) Liska M., Vandeperre L. J, Al-Tabbaa A. (2008). Influence of carbonation on the properties of reactive magnesia cement-based pressed masonry units [J]. Advances in Cement Research, 20(2): 53-64.

6) Liu S.Y., Li C. (2015). Influence of $\mathrm{MgO}$ activity on the stabilization efficiency of carbonated mixing method $[\mathrm{J}]$. Chinese Journal of Geotechnical Engineering, 37(1), 148-155. (in Chinese)

7) Liu S.Y., Qian G.C., Zhang D.W. (2006). The principle and appliciation of dry jet mixing composite foundation [M]. Beijing: China Architecture \& Building Press.

8) Unluer C., Al-Tabbaa A. (2013). Impact of hydrated magnesium carbonate additives on the carbonation of reactive $\mathrm{MgO}$ cements. Cement and Concrete Research. 54:87-97.

9) Van Gerven, T., D. Van Baelen, V. Dutré and C. Vandecasteele (2004). "Influence of carbonation and carbonation methods on leaching of metals from mortars." Cement and Concrete Research, 34(1): 149-156.

10) Vandeperre L. J, Al-Tabbaa A. (2007). Accelerated carbonation of reactive magnesia cements [J]. Advances in Cement Research, 19(2): 67-79.

11) Vandeperre L. J, Liska M, Al-Tabbaa A. (2008). Microstructures of reactive magnesia cement blends [J]. Cement and Concrete Composites, 30(8): 706-714.

12) Yi Y.L., Liska M, Unluer C, Al-Tabbaa A. (2013). Carbonating magnesia for soil stabilization. Canadian Geotechnical Journal. 50: 899-905. 